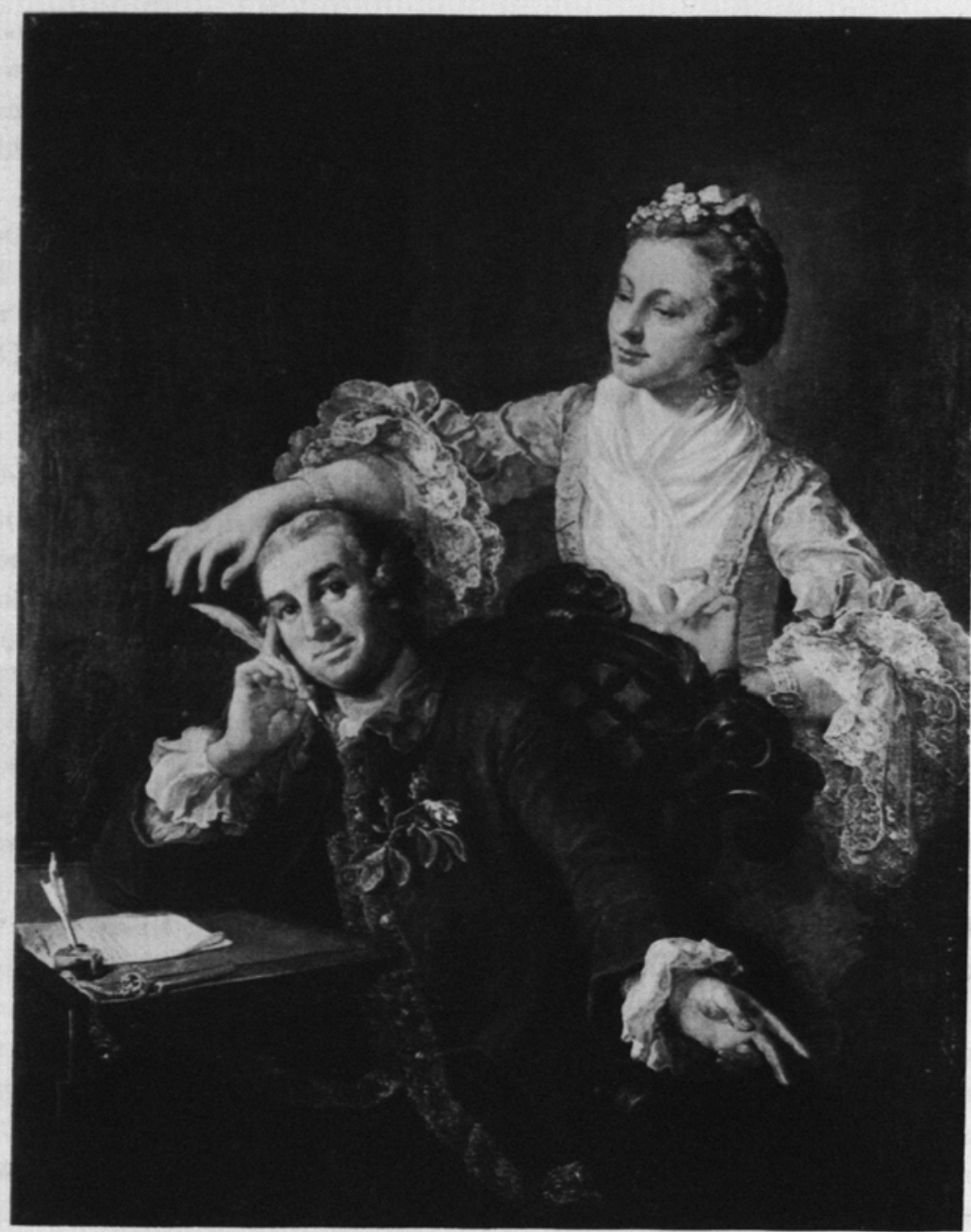

I. William Hogarth, Garrick and his Wife. Hampton Court Palace

Werner Busch

\title{
Hogarths und Reynolds' Porträts des Schauspielers Garrick
}

Die beiden Bilder von Hogarth und Reynolds (Abb. I und 2), die hier behandelt werden sollen, sind zumal in der angelsächsischen Literatur alles andere als unbekannt. Hogarths Bild ist durch quellengeschichtliche Untersuchungen von Antal ${ }^{1}$ und Paulson ${ }^{2}$ gut dokumentiert, die Ergebnisse einer sorgfältigen Röntgenanalyse sind publiziert ${ }^{3}$, zudem ist eine einleuchtende gattungsgeschichtliche Zuordnung zum Typus Ehepaarbildnis unter- nommen worden ${ }^{4}$. Reynolds' Porträt hat die besondere Aufmerksamkeit der Warburg-Schule ge-

${ }^{1}$ F. Antal, Hogarth und seine Stellung in der europäischen Kunst, Dresden 1966 (1. Ausg. London 1962), S. $86 \mathrm{ff}$.

${ }^{2}$ R. Paulson, Hogarth: His Life, Art and Times, 2 Bde., New Haven and London 1971, Bd. 2, S. 235-242, 245 .

3 O. Millar, Garrick and his wife by W. Hogarth, in: The Burlington Magazine 104, 1962, S. 347 f.

${ }^{4} \mathrm{~J}$. Gaus, Ingenium und Ars-Das Ehepaarbildnis Lavoi- 


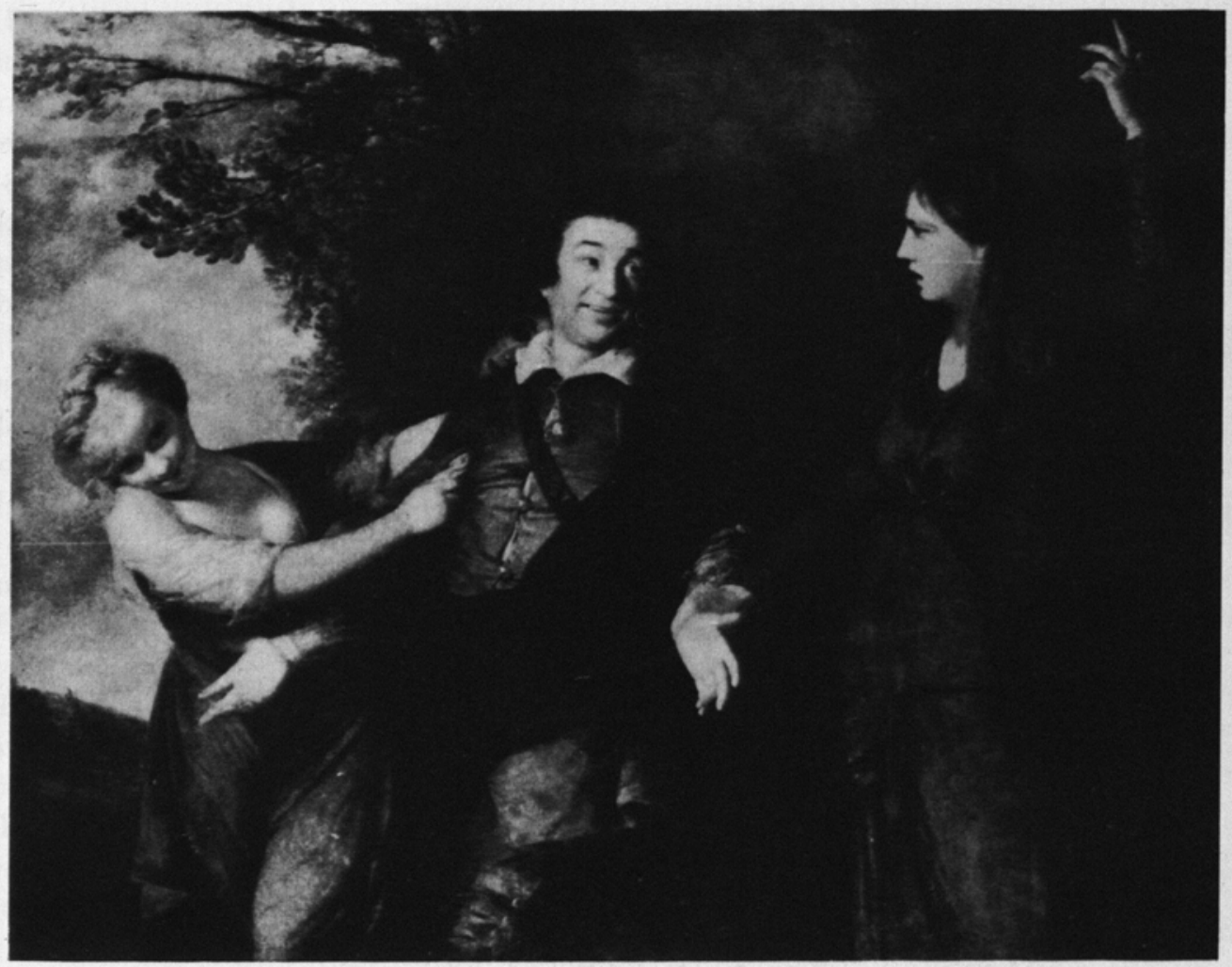

2. Joshua Reynolds, Garrick between Tragedy and Comedy. Engl. Privatbesitz

funden. In Edgar Winds berühmtem Aufsatz über "Humanitätsidee und heroisiertes Porträt in der englischen Kunst des 18 . Jahrhunderts « von $1930 /$ ${ }_{3} \mathrm{I}^{5}$ spielt es eine Schlüsselrolle. Panofsky ${ }^{6}$ und andere haben es unter den verschiedensten Aspekten behandelt. All diesen Untersuchungen ist jedoch zu eigen, daß sie die beiden Bilder immer nur zuordnen, als bloßen Beleg für bestimmte Traditionen nutzen. Ist die Zuordnung erfolgt, so erlischt das Interesse. Im folgenden ist zu zeigen, daß gerade bei diesen Bildern die traditionelle kunsthistorische Platzzuweisung nicht ausreicht.

Es ist von dem überraschenden Phänomen der englischen Kunst des 18 . Jahrhunderts auszugehen, daß bei aller Traditionsgebundenheit kaum ein Kunstwerk ohne gänzliche private, individualistische Anspiélungen oder Verweise auskommt. Vor allem ist das bei einem Austausch von Kunstwerken unter Freunden der Fall. Hogarth wie auch Reynolds waren eng mit Garrick, dem Dargestellten, befreundet. So greift die Interpretation häufig zu kurz, wenn sie allein den scheinbar objektiven Bestand analysiert.

Bei Hogarths Garrick-Porträt (Abb. I) hat die Literatur zwar erkannt, daß die Bildform dem Typus der Museninspiration folgt; von Reynolds Komposition wußten schon die Zeitgenossen, daß sie eine Paraphrase auf das klassische Thema von Herkules am Scheidewege darstellt. Gibt man sich

sier von David und die Ikonographie der Museninspiration, in: Wallraf-Richartz-Jahrbuch 36,1974, S. $199-$ 228, zu Hogarth: S. 222.

s E. Wind, Humanitätsidee und heroisiertes Porträt in der englischen Kunst des I 8. Jahrhunderts, in: Vorträge der Bibliothek Warburg 1930-31, Leipzig-Berlin 1932, S. 1 56-229, zu Reynolds: S. 206-21 1; s. auch ders., Borrowed Attitudes in Hogarth und Reynolds, in: Journal of the Warburg Institute 2, $1938-39$, S. 182-185.

${ }^{6}$ E. Panofsky, Herkules am Scheideweg (= Studien der Bibliothek Warburg, Bd. 18), Berlin 1930, S. 133. 


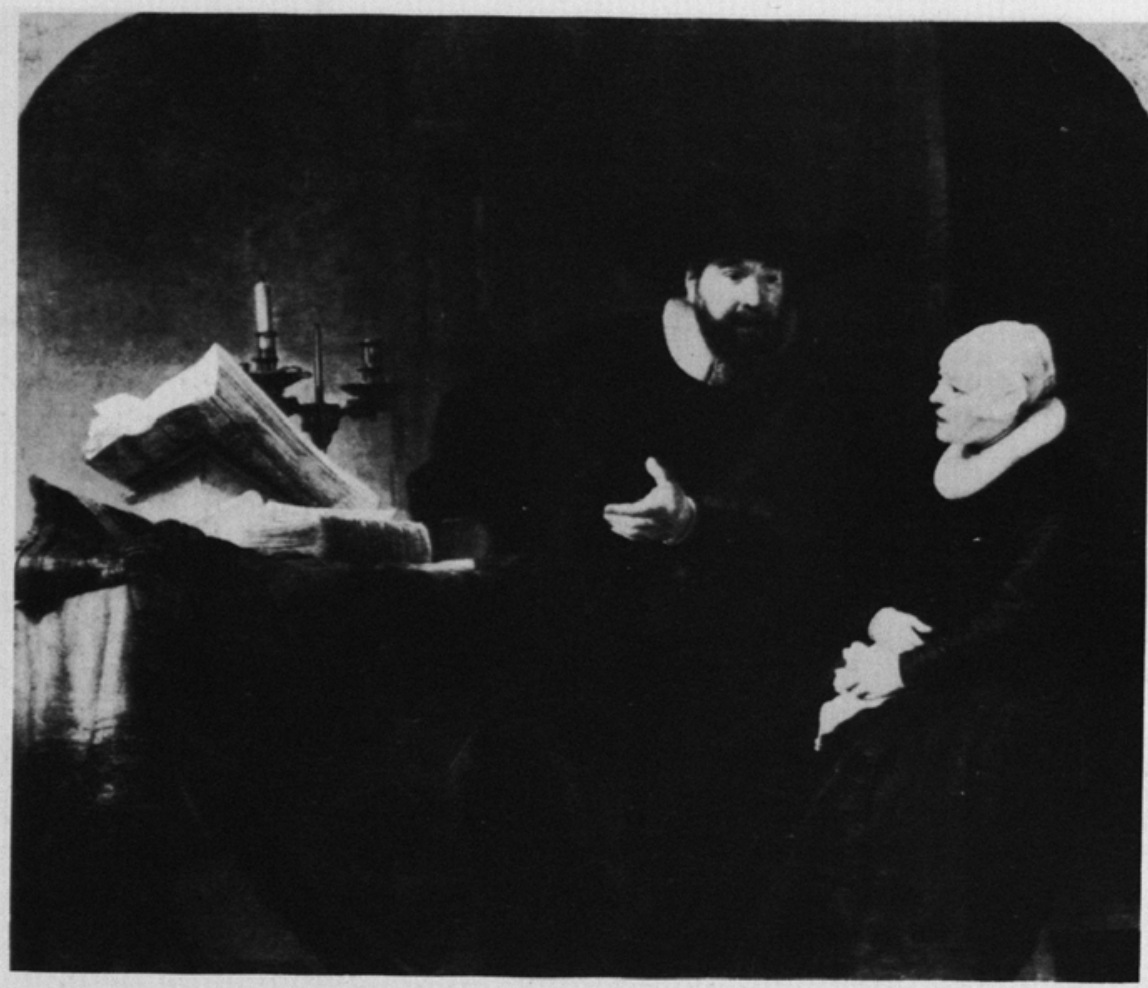

3. Rembrandt, Bildnis des Mennonitenpredigers Anslo mit Frau. Berlin, Staatliche Museen Preußischer Kulturbesitz

jedoch mit diesen Beobachtungen zufrieden, so übersieht man auf beiden Bildern nicht nur eine ganze Sinnschicht, die von der traditionell ikonographischen Sinnschicht etwa glatt abhebbar wäre, sondern man begreift die den eigentlichen Bildsinn ausmachende Dialektik der beiden Sinnbereiche, die man den öffentlichen und den privaten nennen könnte, nicht.

Auf Hogarths Bild von 1757 , das in einem für englische Porträts der Zeit typischen, etwas derben Rokokostil gehalten ist, sitzt der Schauspieler Garrick nachdenklich lächelnd, aber auch ein wenig für den Betrachter posierend auf einem in schweren Barockformen geschnitzten Lehnstuhl an einem Sekretär. Er schreibt, vor dem Original in Hampton Court kann man es entziffern, am Prolog zu Samuel Footes Satire "Taste «. Seine Frau, eine ehemalige Tänzerin, ist, von ihrem Mann unbemerkt, hinter seinen Sessel getreten und versucht ihm spielerisch die Schreibfeder zu entwenden. In der Tat besteht der Witz der Szene darin, daß die Bedeutung des alten Motives der Museninspiration in ihr Gegenteil verkehrt wird?

Das Motiv der Inspiration, dessen Geschichte hier nur angedeutet sei, ist seit den antiken Musensarkophagen in den vielfältigsten Ausprägungen bekannt ${ }^{8}$.

In der mittelalterlichen Buchmalerei etwa kann Melodia den psalmodierenden David im Typus der Orpheusbilder inspirieren, die Evangelisten werden inspiriert dargestellt, dem heiligen Lukas führte zudem, als er die Madonna malte, etwa auf einem Gemälde von Gossaert, ein Engel die Hand, schließlich konnte auch Michelangelo vom Genius

7 Zur "wit «-Theorie in der Malerei des englischen 18. Jahrhunderts s. W. Busch, Nachahmung als bürgerliches Kunstprinzip, Ikonographische Zitate bei Hogarth und in seiner Nachfolge, Hildesheim-New York 1977 , S. 30-49.

${ }^{8}$ Der Abriß folgt Gaus, op. cit. (Anm. 4). 
der Poesie angeregt werden, zumindest hat ihn Cristoforo Allori 162 I so wiedergegeben. In der literarischen Topik ist die Musenanrufung zudem spätestens seit Hesiod geläufig. Man konnte also im I8. Jahrhundert auf eine breite literarische und bildkünstlerische Tradition zurückblicken, allerdings bekommt das Thema zu dieser Zeit einen typisch aufklärerischen Aspekt hinzu: die Inspiration geht häufig von einem Familienmitglied des Inspirierten aus. So konnte das Ehepaarbildnis im I 8. Jahrhundert endgültig den Charakter des genealogischen Dokuments abstreifen und etwa die Ehefrau aktiv am Berufsleben des Mannes teilnehmen lassen. Davids Bildnis des Chemikers Lavoisier mit seiner Frau von 1788 ist sicher das bekannteste Beispiel für diesen Typus. Die ursprünglich platonische Vorstellung einer von außen kommenden Begeisterung hatte das Konzept vom Genius, der die Hand des Ausführenden lenkt, geprägt. Hogarth verkehrt eben dies Motiv in sein Gegenteil. Die Schreibfeder wird nicht geführt, sondern entwendet.

Nun haben Röntgenfotos gezeigt ${ }^{9}$, daß der von späterer Hand, offenbar bald nach Hogarths Tod, einfarbig abgedeckte Hintergrund ursprünglich wesentlich vielfältiger gestaltet war; ein Bücherregal, Kupferstiche und Bilder waren zu sehen, vor allem aber befanden sich oberhalb von Garricks Kopf auf einer geschwungenen Konsole eine Kerze und eine Lichtschere. Von der gerade gelöschten Kerze stieg noch ein wenig Rauch auf. Überschaut man Hogarths Werk, so wird deutlich, daß ein solches Motiv nicht zufällig sein kann. Auf Schritt und Tritt bedient Hogarth sich der klassischen Emblematik, benutzt sie jedoch in seinem Sinne, d.h. er gibt dem einzelnen Emblem eine seinen kodifizierten Sinn modifizierende Bedeutung, die es nur aus dem jeweiligen Bildzusammenhang erfährt. Dieser individuelle und spielerische Umgang mit den Emblemen und, wie man für Hogarth darüber hinaus sagen kann, überhaupt mit dem Bildsinn, den Symbolen und Zeichen, zeigt eine Krise der Bildersprache im 18 . Jahrhundert an, der sich der Künstler nur erwehren kann, indem er sie im Bilde - zum Beispiel mit den Mitteln der Parodie - thematisiert.

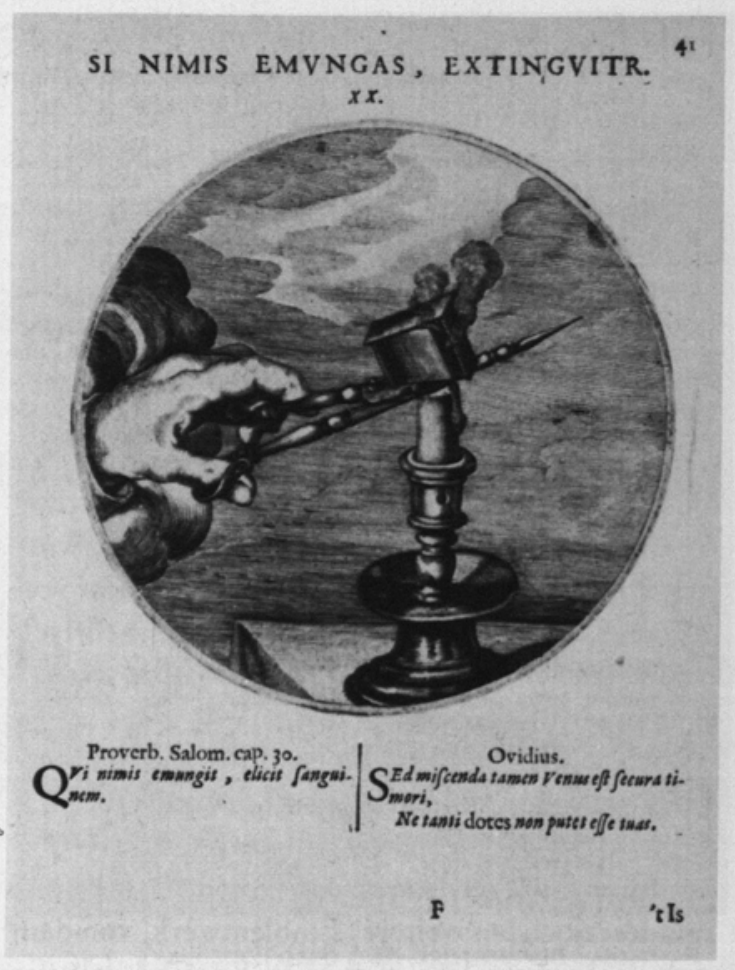

4. Jakob Cats, Maechden-plicht, Emblem Nr. 20

Das Motiv mit der gerade gelöschten Kerze und der Lichtschere läßt sich vor allem in der holländischen Emblematik des 17. Jahrhunderts nachweisen, in der holländischen Kunst hat es auch Anwendung in der Malerei gefunden. Auf Rembrandts Gemälde des Mennonitenpredigers Anslo mit seiner (oder einer) Frau (Abb. 3) von r64I nimmt es eine ähnlich zentrale Position ein wie ursprünglich auf Hogarths Bild ${ }^{10}$. Bei Rembrandt war es relativ problemlos aus der Emblemliteratur zu deuten. Jakob Cats Standardwerk "Emblemata Moralia " gibt bereits die Richtung der Ausdeutung ${ }^{\mathrm{II}}{ }^{\mathrm{I}}$. Weiter hilft jedoch ein anderes verbreitetes Emblemwerk. Bei Covarrubias Orozco in seinen Moralemblemen von $16 \mathrm{IO}^{12}$ steht das

9 Millar, op. cit. (Anm. 3).

${ }^{10} \mathrm{~J}$.-Chr. Klamt, Ut magis luceat, Eine-Miszelle zu Rembrandts "Anslo«, in: Jahrbuch der Berliner Museen N. F. 17,1975, S. $155-165$.

iI J. Cats, Emblemata Moralia, Rotterdam I627, Nr. 20.

${ }_{12}$ C. Orozco, Emblemas morales, Madrid I6ro, Bd. 3 , Nr. 60. 
Emblem für christliche Ermahnung unter dem Lemma ॥t magis luceat $\alpha$. So wie nur eine Kerze, die regelmäßig zurechtgeschnitten wird, gut brennt, so leuchtet auch die Flamme des Glaubens nur bei regelmäßiger Ermahnung und Belehrung durch den Prediger hell auf. Das Emblem kommentiert Rembrandts Bild überzeugend; im Falle Hogarths hilft seine Kenntnis noch nicht weiter. Auch ein geläufiges englisches Emblemwerk, Robert Farleys "Lychnocausia*, London $1638 \mathrm{mit}$ dem englischen Untertitel »Lights Morall Emblems«, das, wie schon der Titel deutlich macht, ausschließlich der Lichtsymbolik gewidmet ist, gibt, obwohl sich die Kombination von Kerze, Kerzenleuchter und Lichtschere mehrfach findet, keinen Hinweis auf die mögliche Bedeutung des Motives bei Hogarth.

Doch von Jakob Cats, dessen »Emblemata Moralia etwa schon für den jungen Reynolds, wie dieser selbst bekundet, die wichtigste Quelle zur Erlernung der Bildersprache darstellten, existiert zumindest noch ein weiteres Emblemwerk, von dem sich nachweisen läßt, daß es in England geläufig war. Cats "Maechden-plicht" erschien zuerst 1618, erlebte eine ganze Reihe von Neuauflagen und Nachdrucken und wurde schon 1637 ins Englische übersetzt. Cats verwendet unverändert sein Emblem aus den "Emblemata Moralia«, stellt es jedoch unter ein neues Motto ${ }^{13}$. Es lautet hier "Si nimis, emungas, extinguitur $\ll$, Wenn du zuviel putzt, verlöscht die Flamme« (Abb. 4). Die falsche Behandlung der Kerze, die verlöscht, wenn man zuviel vom Docht abschneidet, ist also nun das Thema. Dies allein würde die Verwendung des Motives bei Hogarth auch noch nicht eindeutig erklären, doch hat Cats, wie jeder gebildete Emblematiker, seine Erfindung durch Parallelen aus Bibel und antikem Schrifttum kommentiert. Der Bibelvers aus den Sprüchen Salomonis "Wer die Nase hart schneuzt, zwingt Blut heraus * braucht hier nicht zu interessieren, um so mehr jedoch das Ovid-Beispiel. Einigermaßen wörtlich übersetzt lautet es: "Die vereinigende Venus jedoch ist vor der Besorgnis sicher, deine Gaben könnten zu groß sein «, einfacher ausgedrückt: »Nur in der Liebe kann man nicht zuviel tun«. Hogarths Spiel mit der Bedeutung des Emblems wird deutlich. Garrick soll nicht zuviel arbeiten, sonst verdirbt er sein Werk. Darum hat seine Frau die Kerze gelöscht; ihr soll er sich zuwenden, denn allein in der Liebe kann man nicht übertreiben.

Warum der Hintergrund von Hogarths Bild von späterer Hand übermalt wurde, ist unklar. Überliefert ist immerhin, daß Garrick an seinem Porträt Kritik geübt hat, es verblieb bis zu Hogarths Tod in seinem Atelier, womöglich nicht gänzlich vollendet. Wenn man nicht bloß annehmen will, Garrick sei sein Bildnis nicht ähnlich genug gewesen die Sekundärliteratur vermutet dies - so muß man grundsätzliche Meinungsverschiedenheiten über die inhaltliche Konzeption voraussetzen.

Einen ersten Schritt bei der Klärung dieser, wie sich zeigen wird, zentralen Problematik hilft die Beobachtung weiter, daß Hogarths Porträt ganz offensichtlich eine ironische Paraphrase auf J. B. van Loos Bildnis des Colley Cibber mit dessen Tochter (Abb. 5) darstellt ${ }^{14}$. Van Loo hielt sich zwischen 1737 und 1742 in England auf, sein Cibber-Bildnis dürfte vor $174^{\circ}$ entstanden sein, denn die Vermutung liegt nahe, daß Cibber im Bilde mit der Abfassung seiner "Apology for the life of Mr. Colley Cibber, Comedian" beschäftigt ist, die 1740 erschien. Auf diesem Bildnis ist die inspirierende Tochter-Muse in der Tat federführend. Cibber war Garricks direkter Vorläufer, der letzte bedeutende Vertreter eines pathetisch deklamierenden elisabethanischen Theaters. Nach Garricks ersten triumphalen Erfolgen $1740 / 4 \mathrm{I}$ in, wie es seine Zeitgenossen empfanden, natürlicher Sprech- und Spielweise, zog sich Cibber von der Bühne zurück. Sein würdevolles barockes Porträt, das sich noch ganz selbstverständlich der klassischen Versatzstücke eines offiziellen Bildnisses bedient, wird von Hogarth in seinem Garrick-Bildnis durch eine eher private Bildauffassung ersetzt, die sich der Tradition nur noch ironisch vergewissern kann. Statt an einer "Apology « schreibt Garrick am Pro-

${ }^{13} \mathrm{~J}$. Cats, Maechden-plicht ofte Ampt der Ionckvrouwen, in eerbaer Liefde, aen-ghewesen door Sinne-Beelden, Middelburgh I618, Nr. 20.

14 Antal, op. cit. (Anm. I), S. 87 hat dies offenbar zuerst bemerkt. 
$\log$ zu Footes Posse "Taste «. Auf den ersten Blick scheint dies nicht unpassend zu sein. "Taste " gehörte zu den Standardstücken im Repertoire von Garricks Drury Lane Theater, wo es zuerst $175^{2}$ aufgeführt wurde. Foote ${ }^{\text {Is }}$ fungierte auch sonst als Stückelieferant für Garricks Theater. Dennoch gehörte er keineswegs zu Garricks Freunden. Foote, eine Type wie sie nur im englischen 18 . Jahrhundert zu denken ist, ein Schandmaul ersten Ranges, von dem Dr. Johnson, der seine vitale und grobwitzige Natur nicht nur im Theater besonders schätzte, sagte, man könne ihn vorn zur Tür hinauswerfen, dann stünde er hinten schon wieder im Hause - Foote, der mit seinem Little Theatre, Haymarket, beständig va banque spielte, nicht selten mit der Zensur in Konflikt geriet, verspottete Garrick, der sein Talent als Stückeschreiber immerhin schätzte, wo er nur konnte. In Gesprächen, Pamphleten, Zeitungsartikeln, in seinen Stücken selbst versuchte er dem großen Gegner und Konkurrenten beizukommen. Besonders dessen Shakespeare-Begeisterung hatte es ihm angetan. Als Garrick durch glänzende Verträge und sein geschicktes Management von Drury Lane in den Stand gesetzt wurde, sich 1755 als Sommersitz Fuller House in Hampton, gebildet nach dem Modell des Petit Trianon, zu kaufen, als er seine Gärten von Capability Brown, dem ersten Landschaftsarchitekten Englands, gestalten ließ, als er sich gar noch von Robert Adam, dem ersten Architekten des Landes, einen Shakespeare-Tempel in den Garten bauen ließ, da kannte der Spott Footes keine Grenzen mehr. Der Shakespeare-Kult war ihm ebenso zuwider, wie Garricks überaus erfolgreiches Bemühen, mit dem gehobenen Adel auf vertrautem Fuße zu verkehren. Foote dagegen machte sich ein besonderes Vergnügen daraus, jeden Adligen nicht mit seinem Titel, sondern mit seinem Vornamen anzureden. Er war ein stolzer Underdog, der die Freiheiten des Theaters dazu benutzte, sich auszuleben und die Gesellschaft zu verspotten.

Sein Bühnenstück "Taste ${ }^{16}$ auf Hogarths Garrick-Porträt verewigt zu sehen, ist zumindest irritierend, und ganz offensichtlich hat es Hogarth mehr gefallen als Garrick. Denn "Taste « handelt

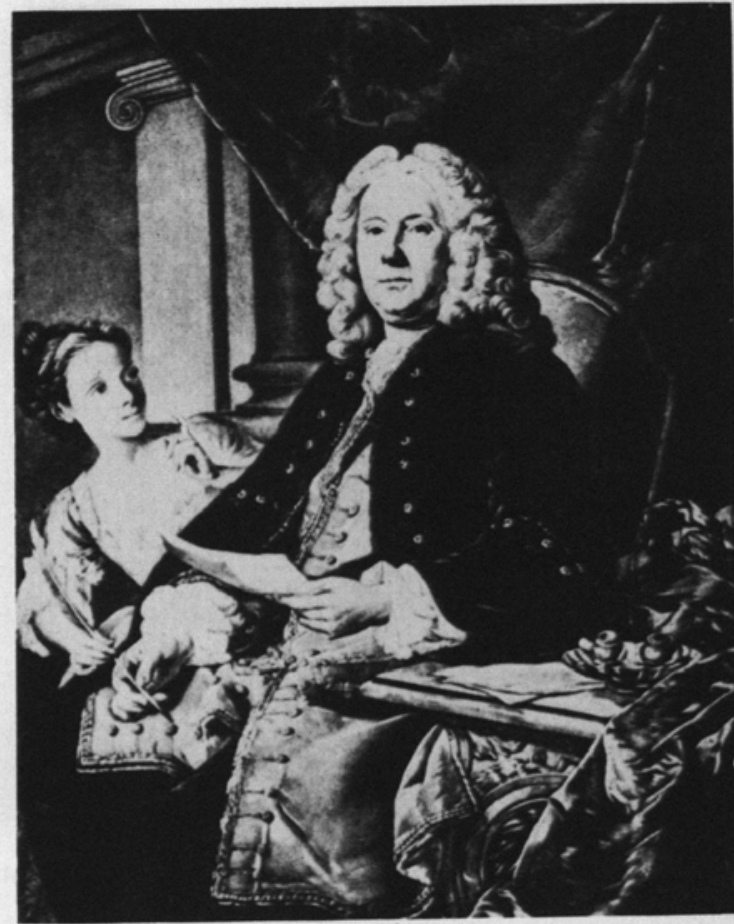

5. Nachstich nach Jean Baptiste van Loo, Bildnis Colley Cibber, Mezzotinto

von Hogarths lebenslangem Zentralthema, seinem $\mathrm{Haß}$ auf Kunstkenner, "connoisseurs « - der Begriff ist in England seit etwa 1720 geläufig $^{17}$ - und auf die Kunsthändler, die den Markt mit Fälschungen alter Meister überschwemmten und den einheimischen Künstlern damit alle Absatzchancen verbauten. "Taste « verspottet den adligen Kenner, der sich auf plumpe Art und Weise und durch unendlich dilettantische Fälschungen hereinlegen läßt. Aber auch die Kunsthändler fliegen am Ende des Stückes auf, ein Kind durchschaut ihren Be-

is $\mathrm{Zu}$ Foote, seinem Verhältnis zu Garrick und zur Theatergeschichte im englischen 18 . Jahrhundert, s. bes. Kat. Ausst. The Georgian Playhouse, Actors, Artists, Audiences and Architecture 1730-1830, Arts Council of Great Britain, Hayward Gallery, London 1975.

${ }^{16}$ Hier zitiert nach der ersten kompletten Werkausgabe der Stücke Footes: S. Foote, The Dramatic Works, 2 Bde., London 1797, Bd. I, S. 7-29; »Taste $\propto$ wurde zum ersten Mal am I I. Januar I752 gegeben.

${ }_{17}$ The Works of Jonathan Richardson, London 1773, III. The Science of a Connaisseur (1. Ausg. 171 5, 2. Ausg. 1725), zum Begriff selbst und der Wissenschaft »connaissance $\alpha$, dort S. 282. 


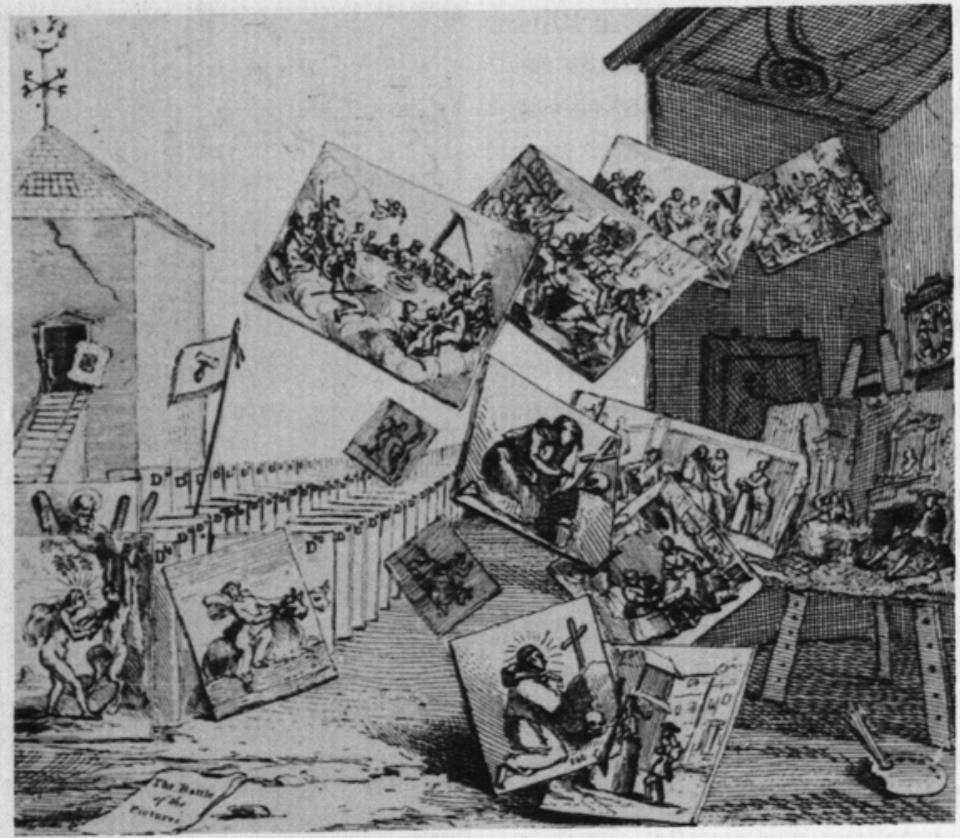

6. William Hogarth, The Battle of the Pictures, Radierung

trug. Um zu verdeutlichen, wie sehr Hogarth eine derartige Posse aus der Seele sprach, sei nur daran erinnert, daß Hogarth selbst mit seinem Freunde, dem Maler Wilson I75I Radierungen à la Rembrandt fertigte, sie auf den Markt bringen, einen berühmten Rembrandtsammler auf den Leim gehen ließ, schließlich den Käufer, einige Kenner und Kunstgenossen zu einem Bankett lud, auf dem der Braten mit eben diesen Rembrandt-Radierungen gespickt war ${ }^{18}$. Die Bloßstellung der Spezialisten konnte drastischer nicht sein. Es ist sogar zu vermuten, daß Hogarth an der Entstehung von Footes Satire nicht ganz unbeteiligt war. Dafür spricht die Namengebung in Footes Stück. Da gibt es nicht nur einen Lord Dupe, den Dupierten, sondern vor allem die Kunsthändler und -fälscher, die Mr. Puff, Brush und Varnish. Die Hauptperson ist Mr. Puff, in Drury Lane von Garrick selbst gespielt, seinen Namen hat offenbar Hogarth erfunden. Auf seiner Radierung »The Battle of the Pictures « von $1744 / 45$ (Abb. 6), auf der seine eigenen Werke einen dramatischen Luftkampf gegen die wertlosen vorgeblich alten Meister austragen, sind die Windrichtungen der Wetterfahne auf dem
Haus des Auktionators P,U,F,S -Pufs benannt ${ }^{19}$. Das spricht ein deutliches Urteil über die Werke dieses Auktionshauses, sie sind puffs, wobei puff nicht nur Windstoß, Hauch bedeutet, sondern figurativ auch Windbeutelei, Betrug, bei dem so getan wird, als ob. Auch die Herkunft des Namens von Mr. Varnish läßt sich nachweisen. Abgesehen davon, daß Hogarth in Wort und Bild beständig gegen die mit varnish, also Firnis, künstlich nachgedunkelten, gefälschten alten Meister zu Felde gezogen ist und für ihn der varnish-Topf zum Inbegriff von Kunstfälscherei und auch getrübtem Kunsturteil geworden ist - es sei nur an "Time smoking a Picture " (Abb. 7) erinnert ${ }^{2 \circ}$ - so gibt es doch auch vorher schon in der Literatur einen Paul Varnish, und zwar in Fieldings "Joseph Andrews " von 1742. Dort ereifert sich Joseph, dem Fieldings Sympathien gelten, über die Reichen, die ihre Häuser mit Möbeln und Kunst vollstopfen, ohne einmal etwas für einen armen Schlucker zu tun. In

${ }^{18}$ S. Paulson, op. cit. (Anm. 2), Bd. 2, S. 11 3-I Is.

19 R. Paulson, Hogarth's Graphic Works, 2 Bde., New Haven and London 1965, Nr. 163.

${ }^{20}$ Ebenda, Nr. 207. 
diesem Zusammenhang zählt Joseph die Namen der Künstler auf, deren Kunstwerke er bei seiner Lady gesehen zu haben meint: "...A Ammyconns, Paul Varnish, Hannibal Scratchs und Hogarths, welches, glaube ich, die Namen der Maler waren $\star^{2 x}$. Der einzige Künstlername, an den er sich richtig erinnert, weil er für ihn verständliche $D i n g e$ malt, ist der Hogarths, die anderen Namen sind aufs Schönste verballhornt. Ammyconn steht für Amigoni, Hogarths Konkurrenten bei der Ausmalung des St. Bartholomews Hospitals, den er mit Mühe verdrängt hatte, wobei die zweite Silbe -con soviel wie betrügen, hereinlegen bedeuten kann. Paul Varnish zielt auf Paolo Veronese, Hannibal Scratch natürlich auf Annibale Carracci. Auch in Footes Stück taucht einmal ein Mr. Scratch - ein Mr. Gekritzel - auf. Es ist mit Sicherheit anzunehmen, daß Fielding dieses Plädoyer für den einheimischen Künstler und gegen die überschätzten ausländischen Maler zusammen mit seinem Freunde Hogarth ausgeheckt hat. Hogarth hat nicht selten zu derartig direkt-indirekten Mitteln gegriffen, wenn es um die Definition seiner Position vor der Kunstöffentlichkeit ging. Folgendes gilt es allerdings zu bedenken, Hogarth hat es mehrfach betont: sein Angriff auf die alten Meister galt nicht diesen selbst, sondern dem Schindluder, das mit ihrem Namen getrieben wurde, er galt den ästhetischen Normen, die sich die adligen Connoisseurs und Grand Touristen in Italien vor den alten Meistern gebildet hatten und die sie plan auf die gegenwärtigen englische Kunst übertrugen. Hogarth konnte das nur für einen absurden Historismus halten. Für ihn waren religiöse und mythologische Themen schlicht »out of date «. Wie sollte er eine âltmeisterliche büßende Magdalena malen, wo schon das Thema für ihn in der Gegenwart gänzlich irrelevant zu sein schien, und warum sollte ein neues Bild gleich alt erscheinen? Sünde, Reue, Buße oder Tat und Rache spielten sich für ihn nicht angesichts einer überirdischen Instanz $a b$, sondern in der Gesellschaft und vor deren Kontrollorganen. Nicht der Verlorene Sohn, sondern sein Rake, nicht Bacchus, sondern sein Grobschmied gingen ihren so oder so zu beurteilenden Vergnügungen nach ${ }^{22}$. Aus seinem bürgerlichen

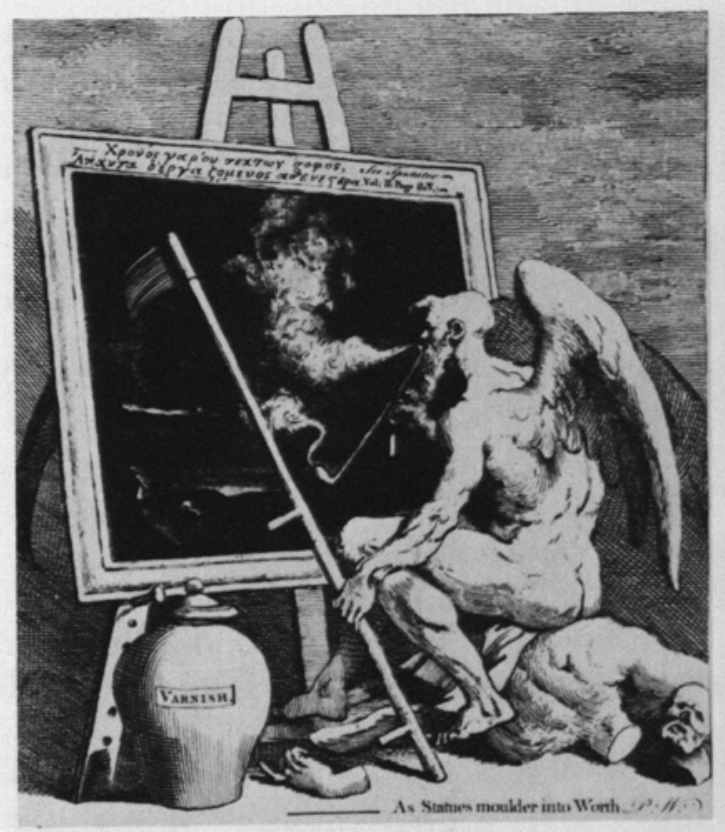

7. William Hogarth, Time smoking a Picture, Radierung mit Mezzotinto

Blickwinkel heraus sollte ein Bild nicht nur schön, sondern auch nützlich sein, über die Gegenwart etwas aussagen. Es sollte seinen Betrachter durch die Darstellungsform ästhetisch reizen - Hogarth hat versucht, diesen Vorgang theoretisch und empirisch zu analysieren -, aber dieser Reiz sollte nicht Selbstzweck bleiben, sondern den Betrachter nur aufnahmefähig für die Mitteilung des Bildes machen.

Was Hogarth und Foote verband, war die gemeinsame Verachtung einer, wie sie meinten, überholten Hochkunst und ihrer ästhetischen Normen; was sie unterschied, war die Tatsache, daß Foote sich damit zufrieden gab, diese Normen und ihre Träger zu verspotten, während Hogarth versuchte, eine neue bürgerliche Kunst und Ästhetik zu schaffen, gegründet auf strenge Wirklichkeitsbeobachtung und deutliche Moralkritik. Hogarths Garrick-Porträt dient unter anderem der Verdeutlichung seines Standpunktes. Das Spiel

${ }^{21}$ Zit. nach H. Fielding, Sämtliche Romane, Bd. I, München 1965, S. 267.

${ }_{22} \mathrm{Zu}$ Hogarths Interpretation der Tradition, s. Busch, op. cit. (Anm. 7), S. 53-65. 
mit den klassischen Bildformeln und -formen erweist sich vor allem als eine Kritik am "taste « des die Hochkunst tragenden Teils der Gesellschaft, zeigt aber auch deutlich Hogarths Position im Streit um die Standortbestimmung der englischen Kunst. Darauf ist nach der Betrachtung des Reynoldschen Bildes einzugehen. Dann wird auch deutlich werden, warum Garrick sich nicht unbedingt für Hogarths Sache hat einspannen lassen wollen.

Reynolds "Garrick between Tragedy and Comedy « (Abb. 2) wurde zuerst 1762 auf der Ausstellung der "Society of Artists « gezeigt. Das Gemälde ist also rund fünf Jahre nach Hogarths Bild entstanden. Garrick erscheint hier zwischen Thalia und Melpomene, den Musen der Komödie und Tragödie. Sie sind an ihrem Typus und ihren Attributen leicht zu erkennen. Thalia mit vollen, sich an der rechten Seite auflösenden blonden Haaren, mit offenherzigem Gewand, nicht nur mit Garrick, sondern auch dem Betrachter kokettierend, hat in der Linken ihre lachende Maske, mit der Rechten zieht sie Garrick am Umhang zu sich herüber; Melpomene ist streng, mit dunklen, von einem Tuch zur Hälfte bedeckten Haaren, hochgeschlossenem Gewand wiedergegeben, im Gürtel trägt sie den Dolch der Tragödie; sie steht aufrecht, Garrick theatralisch ermahnend. Der jedoch kann nur lächelnd bedauernd den Kopf zu ihr zurückwenden, der handgreiflichen Aufforderung der Komödie kann er nicht widerstehen. Aus dem dunklen Schatten der Tragödie begibt er sich in die lichte, freie Landschaft der Komödie. Die Zeitgenossen haben natürlich sofort erkannt, daß Reynolds Bild ganz dem ikonographischen Schema des Herkules am Scheidewege folgt, in Frankreich hieß ein Nachstich gar "Garrick zwischen Tugend und Laster ${ }^{23}$. In England war das Herkules-Thema nicht nur durch Reproduktionsstiche etwa der Bilder von Annibale Carracci und Poussin bekannt, sondern vor allem durch Shaftesburys Abhandlung über die künstlerische Darstellung des Herkulesurteils von $1713^{24}$. Reynolds "wit « besteht in der Umkehrung des Handlungsablaufes; Garrick ist alles andere als standhaft, rafft sich nicht zum dornigen Weg der Tugend auf, sondern folgt ohne viel
Gegenwehr dem Laster. Aber, so wissen wir ja, es ist nur Spiel.

Garrick zwischen Komödie und Tragödie zu sehen, ist aus zweierlei Gründen konsequent. Der Schauspieler war auch auf der Bühne zwischen die beiden Musen eingespannt, ihre Figuren rahmten das Bühnenportal zahlreicher englischer und kontinentaler Bühnen. Zum anderen war Garrick berühmt dafür, in beiden Fächern gleichermaßen vollkommen zu sein. 1757 etwa heißt es im "London Chronicle« zu Garrick: „Ein Schauspieler, der in so staunenswerter Weise das Sublime in den Figuren des Lear oder Hamlet trifft und der darauf die lächerlichsten Erscheinungen darstellen kann, der muß derartig verdoppelte und entgegengesetzte Kräfte besitzen, wie sonst kaum in einem Menschen zu finden und man möchte nicht glauben, daß es noch einmal ein solch tragisch-komisches Genie geben wird «"s. Dr. Johnson, Garricks und Reynolds enger Freund, bestätigte dies, fügte jedoch hinzu "though I liked him best in comedy ${ }^{26}$. Auch Garrick selbst neigte ein wenig mehr der Komödie zu; nicht nur, daß alle Stücke, die er schrieb, Komödien waren, er hatte auch im komischen Fach den größten Erfolg. Als Voltaire Garrick zu Ehren 1766 ins Drury Lane kam, spielte Garrick trotz der Anwesenheit auch König Georgs III. nicht in der Tragödie, sondern eine Doppelrolle in seiner eigenen Posse "Lethe «. Man muß sich klarmachen: in den meisten englischen Theatern der Zeit wurden Tragödie und Komödie an jedem Abend nacheinander gegeben. Von 6 bis 7 Uhr gab es Tragödie; der Mann von Welt, wenn er keine Loge hatte, schickte bereits um 5 oder früher seinen Diener, um Plätze reservieren zu lassen, lö-

${ }_{23}$ Wind, op. cit. (Anm. 5), S. 206; Kat. op. cit. (Anm. Is), Kat. Nr. 33.

24 Anthony, Earl of Shaftesbury, An Essay on Painting, being a Notion of the Historical Draught or Tablature of the Judgement of Hercules, London $171_{3}$; zum Herkulesthema in England s. ferner E. Wind, Shaftesbury as a Patron of Art, in: Journal of the Warburg Institute 2, $193^{8-39}$, S. $185-188$ und J. H. Hagstrum, The Sister Arts, Chicago-London 3. Aufl. 1968, S. 190-197.

2s Zit. in: Kat. op. cit. (Anm. I 5), vor Kat. Nr. I8 (London Chronicle, March 1757).

${ }^{26}$ Boswell's Life of Johnson, ed. George Birkbeck Hill, 6 Bde., Oxford 1887 , Bd. 4 , S. 243. 


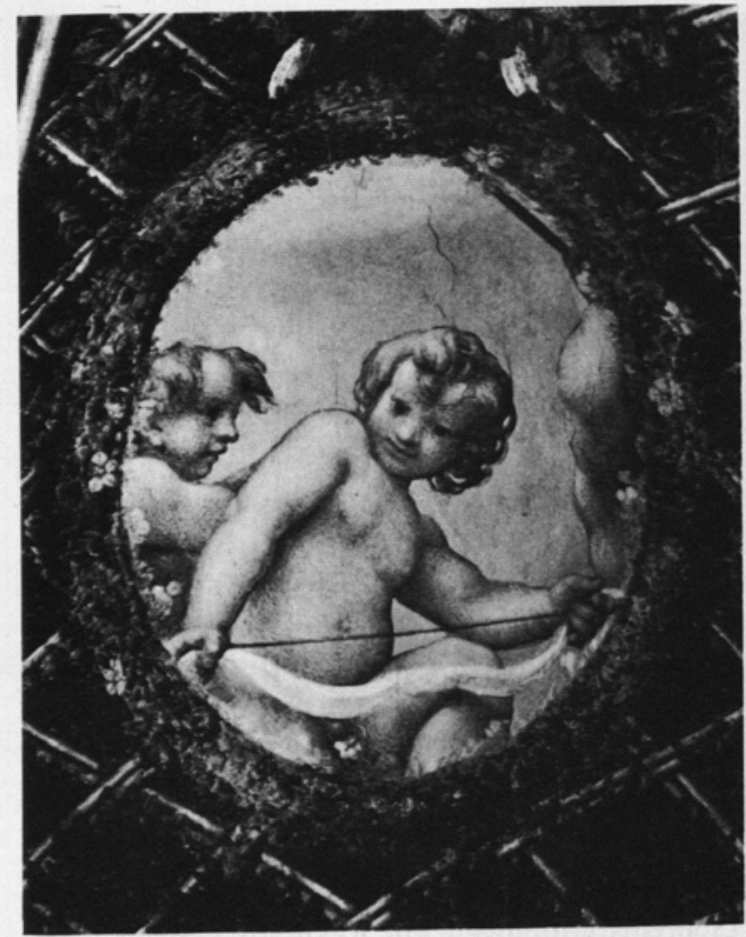

8. Correggio, Engel, Ausschnitt aus dem

Deckenfresko der Camera di San Paolo, Parma

9. Correggio, Hl. Familie mit dem Hl. Hieronymus.

Parma, Galleria

ste ihn dann ab, sah sich die Tragödie an, ging dann, konnte aber auch zur Komödie bleiben. Nun strömte das Volk, denn um 7 schlossen die Geschäfte in der City, und die Komödie wurde vor sehr viel gemischterem Publikum gespielt. Das war das Publikum, das ein Stück durchfallen ließ oder für seine Wiederholung sorgte. Die Tragödie mochte noch so anspruchsvoll sein, die Komödie entschied, ob ein Theater florierte oder nicht. So ist es bezeichnend, daß es zwar eine Reihe von Gemälden gibt, die Garrick in seiner Paraderolle als Richard III. zeigen, daß die Darstellungen in komischen Rollen jedoch bei weitem überwiegen ${ }^{27}$. Erst für die Generation nach Garrick - er gab seine letzte Saison $1775 / 76$ - wurde es möglich, daß ein Schauspieler in nur einem Fache auftrat. Ab 1782 hatte Drury Lane in der berühmten Sarah Siddons die erste reine Tragödin, Reynolds hat sie 1789 als tragische Muse gemalt ${ }^{28}$.

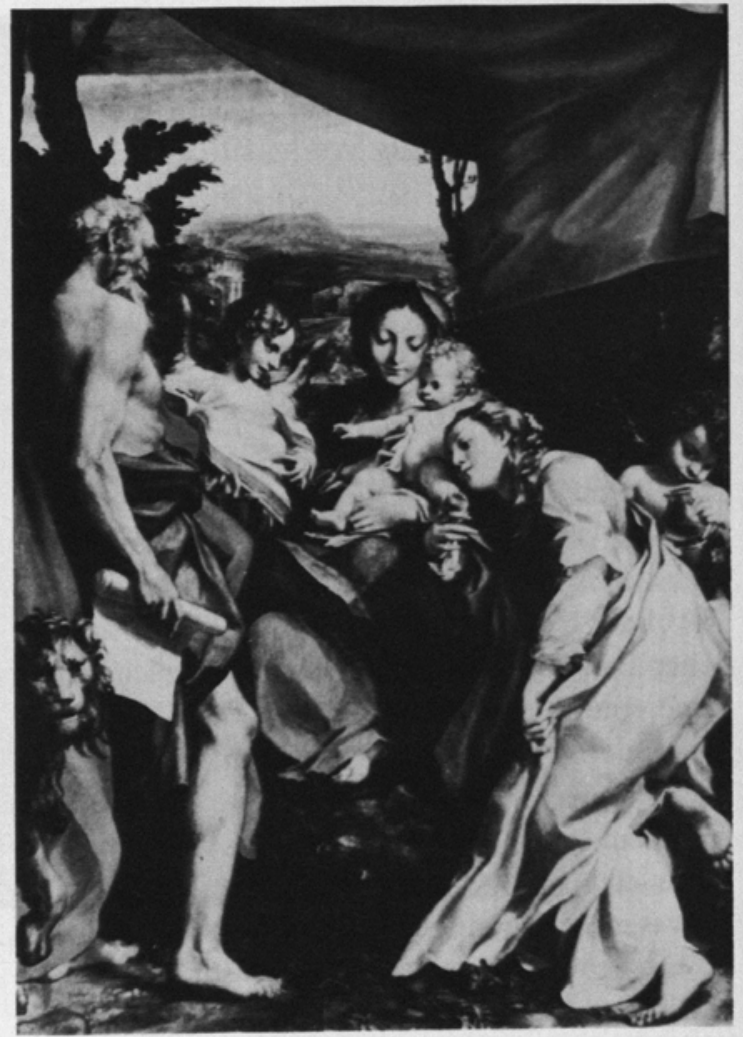

Nun ergeht es Garrick in Reynolds Porträt nicht anders als in Hogarths, er wird als Demonstrationsobjekt für die Erläuterung der kunsttheoretischen Position des Malers selbst benutzt. Denn Reynolds lehnt sich bei der Darstellung der Komödie in Stil und Figurentypus, Körperhaltung und Proportion äußerst eng an Correggio an, die Tragödie folgt dem Pathos, aber auch der Malweise Guido Renis. Das hat man früh erkannt ${ }^{29}$, dabei jedoch übersehen, daß es Reynolds dabei um eine Auseinandersetzung nicht nur mit bestimmten Stilhaltungen, sondern mit ganz bestimmten Bildern ging.

${ }_{27}$ Kat. op. cit. (Anm. I5), Kat. Nr. 19-23, 27-29, 36, 3944 .

${ }^{28}$ Ebenda, Kat. Nr. 98.

29 So etwa bei E. Waterhouse, Painting in Britain, 1530 to 1790, London 1953, S. 168; ders., Reynolds, London 1973, S. 22. 
Reynolds pflegte sein Lebelang Figuren aus eigenen flüchtigen Federskizzen, die er vor allem vor den berühmten Meistern auf seiner Italienreise in den Jahren $1749-\$ 2$ angefertigt hatte, zu kompilieren. Diesen Akt der Kompilation bezeichnete er in seinen "Discourses a als durchaus empfehlenswerte Form künstlerischer Invention ${ }^{30}$. Die Originalität des Künstlers erweise sich gerade in der Kompilation, in der geschickten Neuverwendung und Aneignung klassischer Motive und Darstellungsprinzipien. Häufig klärt ein genaues Studium von Reynolds Reisenotizen über die Herkunft und Genese einer Figurenprägung auf. Nicht anders bei diesem Bild.

Auf der Rückreise von Rom fuhr Reynolds extra über Parma, um die Hauptwerke Correggios zu studieren. Neben den Domfresken hatten es ihm besonders die, wie er schreibt, steinfarbenen Engel in der Camera di San Paolo und die Heilige Familie mit dem $\mathrm{Hl}$. Hieronymus von Correggio angetan. Von letzterem (Abb. 9) heißt es: „Niemals hat mir etwas mehr Freude gemacht, als der Anblick dieses Bildes. Die Haltung der Köpfe, Ausdruck und Kolorit sind von äußerster Vollkommenheit. Es ist sehr fein ausgeführt: kein giallo im Fleisch. Die Schatten scheinen nachträglich mit einer aus Öl und Blei hergestellten dünnen Farbe aufgetragen zu sein. Umrisse des Gesichts, besonders das der Jungfrau, die Lippen usw. nicht zu sehen. Das Rot mit dem Weiß des Gesichts unmerklich vermischt - alles breit « $^{31}$. Reynolds versucht all dies bei der Wiedergabe seiner Komödie nachzuahmen. Der Umriß verschwimmt, die Unterlippe ist nicht zu sehen, Kopfhaltung, Haaranordnung und Schatten sind direkt im Johannesknaben zur Rechten auf Correggios Bild vorgeprägt, der Blick über die Schulter jedoch stammt von einem der "steinfarbenen ", also in Grisaille gemalten Engel in der Camera di San Paolo (Abb. 8). Diese Engel waren in England im 18 . Jahrhundert besonders berühmt, gemalte Kopien des 18 . Jahrhunderts finden sich noch heute etwa in Osterley House vor den Toren Londons, dort hängen sie neben einigen der wichtigsten Werke Reynolds ${ }^{32}$.

Auch für die Tragödie läßt sich Reynolds Arbeitsprozeß genauer verifizieren. $\mathrm{Er}$ hat sehr sorg- fältig Guido Renis »Lot und seine Töchter « (Abb. I0) studiert. Dieses Bild, um 1625 zu datieren, hing, als Reynolds in Rom war, im Palazzo Lancelotti, dort kann er es gesehen haben; es ist überliefert, daß er in Rom die Werke Guidos besonders sorgfältig betrachtet und auch nach Guido kopiert hat. Aber das ist gar nicht einmal nötig. Das Bild Guidos erfreute sich besonders unter Engländern größter Beliebtheit, mehrere Kopien sind überliefert, eine befand sich schon früh in Hampton Court. Kupferstichreproduktionen des 17 . Jahrhunderts existieren, in den 6oer Jahren des 18. Jahrhunderts hat Domenico Cunego noch einmal einen Kupferstich nach dem Bilde für Hamiltons I77I publizierte "Schola Italica Piturae « gefertigt. Engländer bemühten sich beständig, es zu kaufen; am Ende des I 8. Jahrhunderts tauchte es zuerst im englischen Kunsthandel auf, wurde öffentlich ausgestellt und gelangte über Adelsbesitz schließlich in die National Gallery, wo es sich auch heute noch befindet. Auf den ersten Blick scheinen die Übereinstimmungen mit Reynolds Garrick-Porträt nicht sehr weitgehend zu sein. Vergleicht man jedoch im Detail, so steht die direkte Vorbildhaftigkeit des Guidoschen Bildes außer Frage. Zwar hat Reynolds die Kopfhaltung der rechten Tochter Lots bei seiner Tragödie ein wenig abgewandelt, der Kopftypus und der Ausdruck stimmen jedoch wörtlich überein. Der leicht geöffnete Mund, die scharfe Profillinie, die Haarscheitelung, vor allem aber das überhängende Augenlid und die Einbettung des Kopfes in den gleichfarbig dunklen Hintergrund sind als typische Eigenheiten Guidos von Reynolds erkannt und in sein Bild übertragen worden. Auch der dargestellte Moment ist vergleichbar: wie Lots Tochter, so versucht auch die Tragödie mit deutlich weisendem Gestus die Aufmerksamkeit auf sich zu ziehen. Doch Reynolds hat sich nicht nur für die Figur der Tragödie an

\footnotetext{
${ }^{30} \mathrm{~J}$. Reynolds, Discourses on Art, ed. New York-London 1966, S. 3 I (2. Discourse, 1769), S. 87, 97 (6. Discourse, 1774), S. 190-194 (12. Discourse, 1784).

${ }^{31}$ Zit. bei Sir W. Armstrong, Joshua Reynolds, dt. v. E. von Kraatz, München o. J., S. 3 If.

${ }^{32}$ Es handelt sich um sieben Kopien in der "Gallery «, aus dem Besitz des Victoria \& Albert Museum: Inv. Nr. 5930-36-1857.
} 


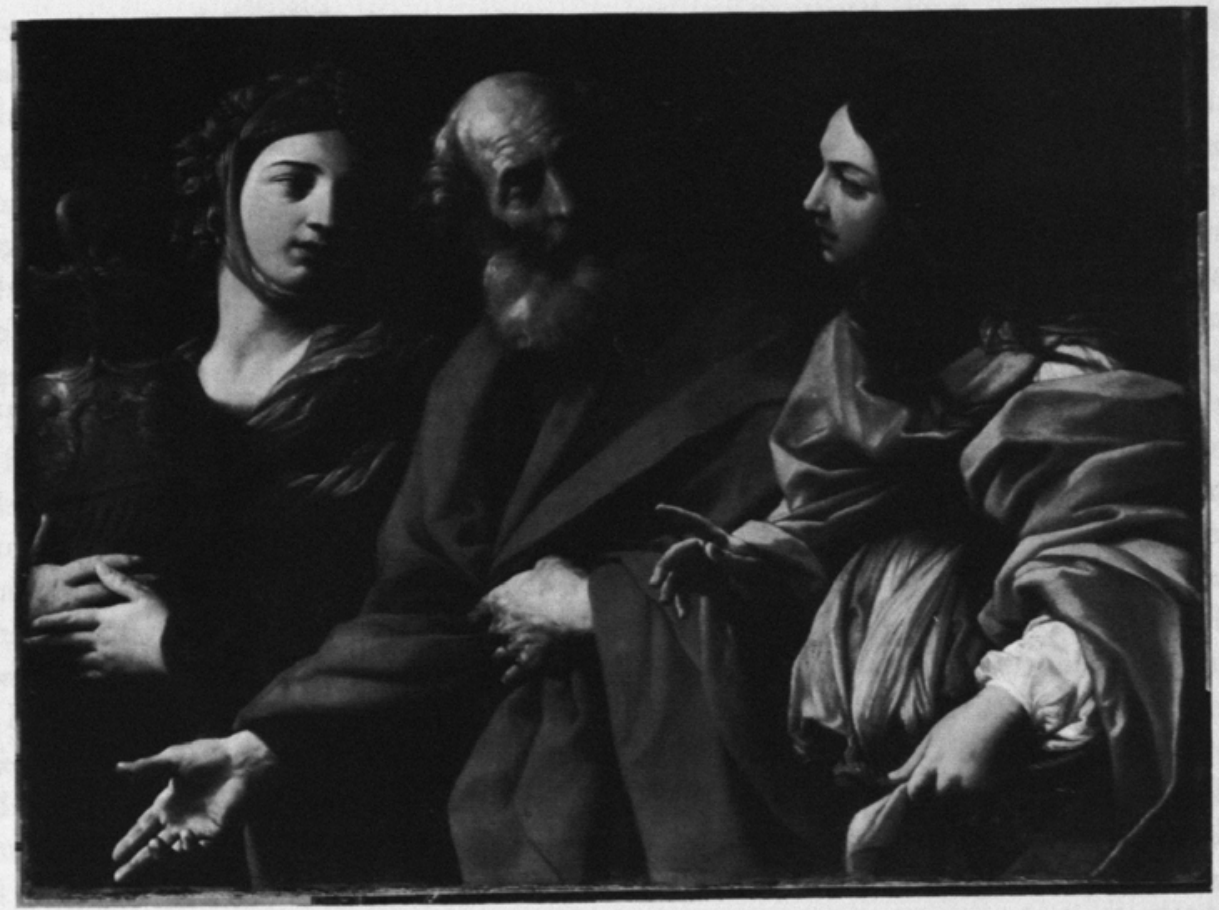

ı. Guido Reni, Lot und seine Töchter. London, National Gallery

Guido Reni gehalten, auch Bildtypus und Figurenkonstellation sind vorbildhaft gewesen. Ist man von der Abhängigkeit noch nicht überzeugt, so räumt eine Beobachtung alle Zweifel aus: Reynolds hat die rechte Hand Lots wörtlich für seinen Garrick kopiert.

Betrachtet man die Gewandung der beiden Musen, so stellt man schnell fest, daß Reynolds nicht nur allgemein ihren Typus charakterisiert, sondern geradezu archäologisch genau vorgeht. Ganz offensichtlich hat er in Rom die Musensarkophage studiert $^{33}$. Melpomene ist mit hochgegürtetem Chiton gekleidet, ihr Mantel ist, einem geläufigen Typus folgend, ein Stück über die Schulter nach vorn gezogen. Thalia dagegen trägt ein dünnes enganliegendes Gewand, ihr Mantel liegt auf der linken Schulter auf und ist nach dem Vorbild der Sarkophage um die Beine geschlungen.

Wohl durch die Sarkophage wird Reynolds auch auf die Idee gebracht worden sein, Musen- und Herkulesmotiv miteinander zu verbinden. Denn Standardattribut der Melpomene auf den Musen- sarkophagen ist die Keule ${ }^{34}$. Die Mythographen des 18. Jahrhunderts erklären sie als Hinweis auf Herkules, seine Taten entsprächen am ehesten dem Begriff des Tragischen. Reynolds dürfte die verbreitete Schrift des Abbé Banier geläufig gewesen sein, der ausdrücklich auf diese Zusammenhänge verweist ${ }^{35}$. Sehen wir Reynolds so weit mit

${ }_{33} \mathrm{M}$. Wegner, Die Musensarkophage (= Die antiken Sarkophagreliefs, hrsg. v. F. Matz, Bd. V, 3), Berlin 1966, S. $105 f$.

${ }_{34}$ Ebenda, S. 106; S. Röttgen, Mengs, Allessandro Albani und Winckelmann - Idee und Gestalt des Parnass in der Villa Albani, in: Storia dell' Arte 30/31, 1977, S. 103f.; E. Schröter, Die Villa Albani als Imago Mundi, in: H. Beck und P. C. Bol (Hrsg.), Forschungen zur Villa Albani (= Frankfurter Forschungen zur Kunst, Bd. 10), Berlin 1982, S. 2366 ., bes. Anm. 199.

3s A. Banier, The Mythology and Fables of the Ancients explain'd from History, 4 Bde., London 1739-40, reprint New York und London 1976, Bd. 2, S. 432 (allerdings wird hier Euterpe als Muse der Tragödie beschrieben, es wird jedoch auch von der Tradition berichtet, nach der Thalia die Keule trägt - so können Komödie und Tragödie gleichermaßen auf Herkules verweisen); in Bd. 4, S. Irgf. führt Banier antike Quellen für die 
Mythologie und antiker Bildtradition vertraut, dann dürfen wir auch vermuten, daß ihm die $\mathrm{Zu}$ ordnung der Musen zu bestimmten Modi geläufig war $^{36}$. Dies wiederum dürfte ihn letztlich auf den Gedanken gebracht haben, seine Musen bestimmten Kunstvorbildern anzugleichen, denen Kunsttheorie und Vitenliteratur bestimmte modale Qualitäten zuschrieben: dem Correggio eben sanfte Lieblichkeit, dem Guido Reni herbe Strenge. So verband die Harmonienlehre die Melpomene auch mit dem strengen dorischen Modus.

Doch auch für den grundsätzlichen Aufbau - ein Dichter zwischen Komödie und Tragödie - läßt sich ein antiker Vorläufer beibringen, den Reynolds in Rom gesehen haben mag. In der Villa Albani befindet sich noch heute das Miniaturrelief des römischen Komödiendichters Persius auf Lapislazuli, gerahmt von den Musen der Komödie und der Tragödie ${ }^{37}$. Reynolds kann es nicht in situ gesehen haben, die Villa Albani wurde erst nach seinem Rombesuch fertiggestellt, offenbar stammt das Relief jedoch aus dem Besitz der Farnese. Ein anderes, neuzeitliches Kunstwerk der Villa Albani dürfte Reynolds nicht gekannt haben, obwohl bis zu einer gewissen Grenze verblüffende Übereinstimmungen mit seinem Bild festzustellen sind. Mengs berühmter ${ }^{P a r n a} ß_{*^{3}}{ }^{8}$ ist 1761 , ein Jahr vor Reynolds *Garrick « vollendet worden. Die Charakterisierungen der beiden Musen Thalia und Melpomene kommen einander erstaunlich nahe, auch Mengs ordnet linke und rechte Bildhälfte unterschiedlichen Auffassungen - ernst und heiter zu. Ohne das hier weiter verfolgen zu wollen: auch das Streben nach archäologischer Genauigkeit läßt sich vergleichen. Beide gehen eigentlich schon kunsthistorisch vor, Mengs stärker an der Antike, Reynolds an den klassischen italienischen Vorbildern orientiert. Bei beiden, so wird man auch sagen können, ist diese reflektive Tendenz Ausdruck eines nicht mehr ungebrochenen Verhältnisses zur Tradition.

So eklektisch und uns fremd Reynolds Vorgehen auch scheinen mag, es ist zugleich programmatisch. Zum einen versucht Reynolds den Topos der klassizistischen Kunsttheorie, der die Vereinigung der herausragenden Eigenschaften der berühmte- sten Künstler fordert, in die Praxis umzusetzen. Zum anderen spiegeln Correggio und Guido Reni zwei Pole wider, zwischen denen Reynolds lange schwankte, allerdings nicht nur er, sondern auch die englische Kunstöffentlichkeit.

Der Zarttonigkeit Correggios, seiner *grace and elegance, wie Reynolds selbst schreibt ${ }^{39}$, stand das Pathos, der Ernst, die schwerere, dunklere Farbigkeit der Bologneser Schule gegenüber. Hinzu kam, daß es Reynolds wie schon Hogarth, wenn auch mit anderer Zielsetzung, vor ihm um eine Aufwertung der Porträtmalerei ging. Die Porträtmalerei, in der Rangordnung der Gattungen als bloße Imitation der Natur in der klassischen Kunsttheorie niedrig eingestuft, sollte zum Range der Historienmalerei, einer Ideenkunst, hochstilisiert werden. Reynolds hat diesen Prozeß der Nobilitierung des Niederen, seine Annäherung an die "general idea* durch einen sogenannten *composite style* insbesondere im 4. "Discourse* beschrieben $^{40}$.

Für John Hoadly, Freund Hogarths und Garricks, reichte die spielerische Verwendung des $\mathrm{Fe}$ dermotives in Hogarths Garrick-Bildnis aus, *um es über die formale Geistlosigkeit eines bloßen

Gleichsetzung von Herkules und Sol Apoll an, in denen auch Herkules als Musagethes bezeichnet wird. Sieht auch Reynolds Garrick als Musenführer, so ist der - wit « ein doppelter: denn zweifellos führen die Musen Garrick und nicht er sie, und zudem folgt er auch noch der falschen Muse.

${ }^{36}$ Dazu A. Warburg, Gesammelte Schriften, hrsg. von der Bibliothek Warburg, Bd. I, Leipzig-Berlin 1932, S. 412-415 (zu S. 270); E. Wind, Pagan Mysteries in the Renaissance, ed. Harmondsworth 1967 , bes. S. $265-$ 269; J. Bialostocki, Stil und Ikonographie, Dresden 1966, S. 18.

37 Schröter, op. cit. (Anm. 34), S. 236, Anm. 198, ich danke der Autorin für freundliche Auskünfte zum genannten Relief; A. Allroggen-Bredel, Die Antikensammlung in der Villa Albani zur Zeit Winckelmanns, in: Forschungen zur Villa Albani, op. cit. (Anm. 34), S. 375 (A 61 3 ) und Taf. 96, Abb. 197.

${ }^{8}$ Röttgen, op. cit. (Anm. 34) und Schröter, op. cit. (Anm. 34), S. 228-257.

39 Reynolds, op. cit. (Anm. 30), S. 67f. (4. Discourse, 1771).

40 Ebenda, S. 67 (4. Discourse, 1771); zur Auffassung der Porträtmalerei auch ebenda, S. 52 (3. Discourse, 1770) und S. 177 (1 I. Discourse, 1782). 
Porträts zu erheben * $^{41}$. Reynolds geht noch einen Schritt weiter. Er paraphrasiert nicht nur das klassische Thema, den ikonographischen Typus, sondern er dehnt das Wahlmotiv auf den künstlerischen und ästhetischen Bereich aus, auch der Künstler befindet sich am Scheideweg. Man kann Reynolds bewußten Eklektizismus - der Begriff ist bezeichnenderweise mit durchaus positiver Konnotation erst 1763 von Winckelmann geprägt worden $^{42}$ - als eine Vorform des Historismus begreifen. In der Erfahrung, daß die Gegenwart offenbar keinen eigenen Stil, kein eigenes Selbstverständnis hervorbringt, besinnt Reynolds sich auf die vorbildhafte Vergangenheit, er zitiert Kunst, nicht als selbstverständlicher Teilhaber an der Tradition, sondern aus dem Gefühl geschichtlicher Distanz heraus. Der Sinn eines Bildes ruht bei Reynolds nicht mehr allein in ihm selbst, sondern erschließt sich aus der Reflexion seiner widersprüchlichen Teile. Diese Widersprüche lösen sich, so Horace Walpole i 77 I zu den Bildern Reynolds, durch das Prinzip des bewußt eingesetzten -wit * ${ }^{43}$, des Witzes, also etwa durch die Umkehrung der ursprünglichen Bedeutung eines Motives. Die intellektuelle Leistung des Betrachters bringt erst, auf der Basis seiner kunsthistorischen Kenntnisse, den Bildsinn hervor. Er, der Betrachter-das ist fast schon romantisch gedacht - vollendet das Bild erst eigentlich"4. Nun ist der Gedanke, den Betrachter an der Vollendung eines Werkes teilhaben zu lassen, nicht gänzlich neu. Der Topos, der Maler müsse der Imagination des Betrachters durch das bloße Anklingenlassen eines Gedankens oder eines Motives Raum geben, findet sich gar schon bei Plinius. In abgewandelter Form läßt er sich in der Dichtungstheorie durch die Jahrhunderte hindurch nachweisen. Im I 8. Jahrhundert jedoch taucht er nicht nur in zahllosen Variationen auf, sondern gewinnt auch eine neue Dimension hinzu. Roger de Piles lobt 1699 die bloße Skizze als vollwertiges Kunstwerk, denn sie gebe der Einbildungskraft die Möglichkeitn individueller Vollendung. Jeder könne das Fehlende nach seinem Geschmack ergänzen"s. Diese Beobachtung zeigt Einsicht in die Relativität des Geschmacksurteils und einmal mehr, wie sehr sich die französischen
Theoretiker am Ende der »Querelles « über die Bedingtheit allen Urteilens und damit auch die $\mathrm{Hi}$ storizität des Kunstwerkes selbst im klaren waren $^{46}$. De Piles Traktat wurde bereits 1707 ins Englische übersetzt, noch Reynolds ist es absolut geläufig, als er die *unfinished manner* von Gainsborough, so sehr sie seinen eigenen Grundprinzipien widersprechen mußte, durchaus zu loben wußte ${ }^{47}$. Das 18 . Jahrhundert analysiert den angesprochenen Vorgang der Vollendung durch den Betrachter wahrnehmungspsychologisch. Man nahm an, daß Bilder eine eigene kinetische Energie besäßen, die besagte Reaktionen beim Betrachter auslöste. Die Möglichkeit, dem Betrachter damit Vergnügen zu bereiten, wurde als besondere Qualität des Kunstwerkes angesehen. Nun ist diese Potenz nicht unbedingt dem Reynoldschen und auch nicht dem Hogarthschen Bild zuzuschreiben. Nicht spontane psychische Reaktion fördert ihre Bedeutung zutage, sondern intellektuelles Reflektieren. Doch die Wahrnehmungsästhetiker haben auch diese Möglichkeit mitbedacht. Bei Alexander Gerard in seinem "Essay on Taste* von 1759 , der auch für Hogarth in mehrfacher Hinsicht wichtig gewesen ist, heißt es: der Betrachter liebe bloße Anspielungen und genieße es, wenn ein Werk *leaves the full meaning to be guessed at ${ }^{-}$- wenn ein Werk die vollständige Bedeutung zu erraten

4t John Hoadley an Joseph Warton, 21. April I 757, zitiert bei: J. Nichols and G. Steevens, The Genuine Works of William Hogarth, 3 Bde., London $1808-1817$, Bd. I, S. 212.

${ }^{4}$ Zum Eklektizismusbegriff s. Busch, op. cit. (Anm. 7), S. 22-25 (Zusammenfassung der Kontroverse D. Mahon - R. Lee).

${ }_{43} \mathrm{H}$. Walpole, Anecdotes of Painting, 3 Bde., ed. London 1888, Bd. I, S. XVII.

44 E. Rothstein, *Ideal Presence* and the $*$ Non Finito * in Eighteenth-Century Aesthetics, in: Eighteenth-Century Studies 9, 1975-76, S. $307-332$.

45 R. de Piles, Abrégé de la vie des peintres, 2. Aufl. Paris I7Is (1. Aufl. 1699), S. 69.

${ }^{4} \mathrm{~S}$. vor allem E. R. Jauss' Einleitung zum Nachdruck von Charles Perrault, Parallèle des Anciens et des Modernes, München 1964, s. auch ders., Literaturgeschichte als Provokation, S. Aufl., Frankfurt 1974, bes. S. 32-35.

47 Reynolds, op. cit. (Anm. 30), S. 217-229, bes. S. 26-228 (14. Discourse, 1788), S. 228: *the imagination supplies the rest*, s. dazu auch E. H. Gombrich, Art and Illusion, London-New York 1960, S. $199 \mathrm{f}$. 


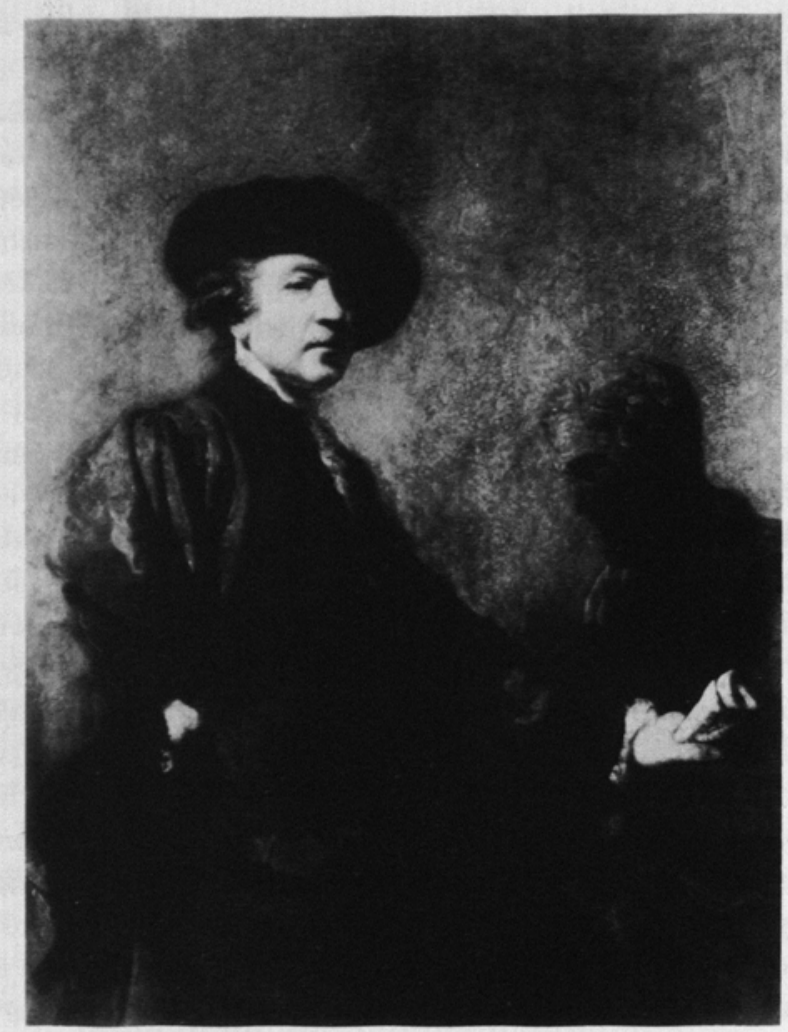

I I. Joshua Reynolds, Selbstbildnis vor der Büste Michelangelos. London, Royal Academy

übrig läßt $\mathrm{t}^{4}$. Die psychologische Theorie des 18 . Jahrhunderts rechnet notwendig mit der Komplizenschaft von Künstler und Betrachter. Ein weiteres Reynoldsches Beispiel mag dies verdeutlichen.

Der Konzeptcharakter seines mit einiger Sicherheit 1773 zu datierenden Selbstbildnisses (Abb. II) wird erst deutlich, wenn man erkennt, daß sich Reynolds in diesem offiziellen Porträt zwar vor einer Michelangelobüste, aber in Stil und Bildtypus der Rembrandt-Selbstbildnisse malt. Wieder sind damit zwei Pole seines künstlerischen Kosmos angegeben, deren Vermittlung er nicht selbst im Bilde leistet, sondern die er dem Betrachter zu leisten aufgibt. Sinnvoll sind die Widersprüche im Bilde für Reynolds insofern, als er damit den Rang des Bildnisses dokumentieren kann. Der Rembrandtstil ist der Gattung Porträt besonders angemessen, er ist in der Lage, den Charakter des Dargestellten am ehesten zu treffen, die Anwesenheit
Michelangelos hat die idealistische Nobilitierung zu besorgen. In Reynolds 5. Diskurs von $177^{2}$ heißt es: "Raffael hat mehr Geschmack und Reiz, Michelangelo mehr Genius und Imagination « ${ }^{49}$, zwei Jahre später im 6. Diskurs zu Rembrandt: »er wählt seine Objekte nicht aus, sondern ergreift die individuelle Natur, so wie er sie findet ${ }^{50}$. Von Rembrandt kann er lernen, wie das zu malen ist, was man sieht, von Michelangelo hofft er zur Idee geführt zu werden, die dem Kunstwerk erst eigentlich seinen Rang gibt.

Es gilt an diesem Punkt vorläufig zusammenzufassen. Hogarth und Reynolds gehen bei ihren Porträts des Schauspielers Garrick sehr ähnlich vor. Beide arbeiten mit dem Zitat klassisch ikono-

$4^{8} \mathrm{~A}$. Gerard, An Essay on Taste, 3. Aufl. Edinburgh 1780 (1. Aufl. 1759), S. 4.

49 Reynolds, op. cit. (Anm. 30), S. 76 (4. Discourse, 1772).

so Ebenda, S. 94 (6. Discourse, 1774). 
graphischer Schemata, deren ursprünglichen Sinn sie durch Verkehrung in sein Gegenteil parodieren, das Resultat dieses Vorganges gibt individuellen Sinn für den neuen Gegenstand frei - und nur für ihn. Beide nutzen die neue Sinnkonstellation, die dem Betrachter herauszufinden aufgegeben ist, in einem zweiten Schritt für ihre eigenen Zwecke, als Demonstration und Rechtfertigung ihrer eigenen künstlerischen und kunsttheoretischen Position. Dabei dient ihnen die den Witz ermöglichende Diskrepanz der Teile, bzw. Sinnbereiche dazu, die Pole zu benennen, zwischen die sie ihre Kunst eingespannt sehen. Die Pole jedoch sind bei Hogarth und Reynolds nicht dieselben. Reynolds hat die Spannung auszuhalten, die der Versuch der Vereinigung unterschiedlicher Kunstformen mit sich bringt, Hogarth jedoch die Diskrepanz zwischen Kunst und Natur bzw. Realität. So spielerisch er damit im Garrick-Porträt auch umgeht Garrick hat zwischen seiner künstlerischen Arbeit und der Liebe zu seiner Frau zu wählen -, wie existentiell das Problem für Hogarth war, wird durch das Zitat von Footes "Taste «-Stück immerhin angedeutet. Die Kunst der Zeit sah er als künstlich, verlogen, aus der Gegenwartserfahrung heraus als nicht zu rechtfertigen an. Die klassischen Themen, besonders die christlichen, schienen ihm keinen Sinn mehr zu geben. So tendierte er in der Tat zur Natur. Doch die Realitätsaneignung in der Kunst erwies sich als problematisch: wie sollte sich die Kunst noch als Kunst erweisen, vom bloßen Handwerk unterscheiden? Hogarth versuchte das Problem einerseits dadurch zu lösen, daß er von der Kunst die Erfindung moralischer Geschichten forderte, die aus der Gegenwart zu erwachsen hatten. Der moralische Anspruch hatte nicht nur die Aufgabe, die ungewöhnlichen, unklassischen Themen zu rechtfertigen, sondern auch zu nobilitieren, dem Rang eines Historienbildes anzugleichen. Andererseits suchte Hogarth die formalen Prinzipien zu bestimmen, die bei der künstlerischen Umsetzung derartiger Geschichten allein von $\mathrm{Be}-$ lang waren. Das erwies sich wiederum als schwierig. Inhalt und Form gerieten in ein widersprüchliches Verhältnis. Der, nach klassischen Vorstellungen, niedere Inhalt konnte, das begriff Hogarth so- fort, nicht in schöner Form erscheinen, wollte er den Inhalt nicht entwerten. Hogarths Lösung: die klassische Form trat nur in abgeleiteter, verkleideter Form auf. Der Kenner konnte unter dem Flor des Alltäglichen klassische Schemata finden. $\mathrm{Zu}$ diesem Verfahren griff übrigens am Ende des 16. Jahrhunderts schon Annibale Carracci bei seinen Genrebildern ${ }^{\text {sI }}$.

Die schöne Form, von Hogarth in seiner "Analysis of Beauty « von 1753 auf das Prinzip der schönen geschwungenen Linie reduziert, sollte zudem im kompositorischen Gerüst der Bilder zum Tragen kommen. Das brachte eine zusätzliche Schwierigkeit. Denn nun waren zwei Wahrnehmungsweisen gefordert. Der Betrachter mußte das Bild als Bild, als Illusion wahrnehmen, und er mußte das abstrakte, schönheitliche Liniengespinst auf der Fläche nachvollziehen. Das Vergnügen, dieses Linien- und Formgebilde zu verfolgen, sollte ihn schließlich auch zum Nachgrübeln über den Inhalt führen. Der Widerspruch zwischen diesen beiden Wahrnehmungsweisen allerdings blieb zumeist unaufgehoben.

An diesem Punkt ist Hogarths Berührung mit der zeitgenössischen Wahrnehmungsästhetik am deutlichsten. Wenn David Hume $174^{8}$ schreibt "each mind perceives a different beauty ${ }^{{ }^{52}}$ - »jeder Sinn nimmt Schönheit unterschiedlich auf « - und daraus folgert, daß es nutzlos sei, nach der absoluten Schönheit, der Schönheit an sich, zu suchen, dann setzt er damit einerseits die Gültigkeit klassischer Norm außer Kraft und bindet andererseits den Begriff der Schönheit an die Empirie und die Geschichte. Zu diesem Ergebnis kam Hogarth nolens volens auch. Seine ästhetische Werteskala verschob sich. Nicht die Ganzheitlichkeit, die Vollendung des Kunstproduktes, das sich damit von sei-

sI D. Posner, Annibale Carracci (= National Gallery of Art, Kress Foundation Studies in the History of European Art, Nr. 5), London 1971 , Bd. I, S. 7, 10, 14 f.

s2 Zitiert nach D. Hume, Essays Moral, Political, and Literary (= The World's Classics Bd. 33, The Works of David Hume, Bd. I), London, Edinburgh, etc. 1904, S. $234 \mathrm{f}$., der vollständige Satz lautet: »Beauty is no quality in things themselves: it exists merely in the mind which contemplates them; and each mind perceives a different beauty. (one person may even perceive deformity, where another is sensible of beauty). « 
nem Schöpfer löst, stand für ihn an erster Stelle, sondern sein Hauptziel war es, den Nachvollzug des Entstehungsprozesses zu ermöglichen. Den Betrachter reizt es, so schreibt Hogarth, Rätsel zu lösen, seine Gedanken im Bilde spazierenfahren zu lassen, er begibt sich auf "a wanton kind of chase " $\$ 3$ - weine wollüstige Art von Jagd «. "Love of pursuit ${ }^{54}$, die Liebe etwas zu verfolgen, treibt ihn voran. Allerdings: hat der Betrachter die Anspielungen verstanden, offenbart sich ihm, besonders wenn es sich um einen Bild-»wit handelt, der Bildsinn in Form eines "aha«-Effektes.

Hier ist ein prekärer Punkt erreicht, denn die Kunst begibt sich des Anspruchs auf Dauer. Tendenziell erschöpft sich das Kunstwerk in seiner Entschlüsselung. In der Erinnerung verbleibt, zumindest theoretisch, nicht das Bild, sondern sein "wit«, und der tendiert dazu, vor allem bei Wiederholung, schal zu werden. Dem möchte Hogarth durch seine Forderung nach einer geradezu autonomen, in einem eigenen Wahrnehmungsakt erfahrbaren Formschönheit entgegenwirken.

Im Garrick-Bild scheinen diese Widersprüche problemlos vermittelt zu sein. Die elegante Form, überall den Forderungen der geschwungenen Schönheitslinie folgend, scheint dem Gegenstand gänzlich angemessen. Garrick war berühmt für seine graziösen, geradezu schwerelosen Bewegungen, seine Frau schließlich Tänzerin. In Hogarths "Analysis« ist der Tanz Inbegriff schöner, fließender Bewegungs". Doch gerade diese Grazie, formales Ziel der künstlerischen Bemühungen Hogarths, war ihm im Leben verdächtig. Die Posse „Taste« konterkariert die elegante Erscheinungsform der Familie Garrick. Form und Norm koexistieren nur äußerlich.

Bei seinen Zeitgenossen stieß Hogarth mit seinem Konzept auf wenig Verständnis, die entscheidenden theoretischen, aber auch ganz praktischen Auseinandersetzungen mit seinen Künstlerkollegen über den weiteren Gang der englischen Kunst führte er in den Jahren 1759 bis 1762 , also genau in der Zeit zwischen seinem und Reynolds Garrickporträt.

Diese Auseinandersetzungen seien abschließend kurz referiert, sie machen die Positionen Hogarths und Reynolds deutlich, aber erhellen auch den Standpunkt Garricks schlaglichtartigs6. 1759 veröffentlichte Reynolds in der Zeitschrift $»$ The Idler * eine dreiteilige Brieffolge, die, ohne daß $\mathrm{Na}$ men genannt würden, gegen Hogarths Auffassung von der Kunst gerichtet war. Damit war der Streit der Künstler über den weiteren Gang der englischen Kunst offen ausgebrochen. Der zweite Brief, betitelt "Grand Style of Painting «, wirft Hogarth indirekt vor, er vermische den holländischen mit dem italienischen Stil, das sei eine Vermengung von gänzlich Unverträglichem, wahre Kunst könne dabei nicht entstehen, plumpe $\mathrm{Na}$ turnachahmung und Idealisierung schlössen einander aus. Auf den deutlichen Widerspruch zu Reynolds eigenem künstlerischen Vorgehen sei hier nur verwiesen.

Reynolds entwickelt im folgenden sein Idealbild vom gebildeten Künstler, der allein in der Lage sei, auf der Basis idealistischer Kunsttheorie im "grand style« zu malen. 1757 bei einem Künstlertreffen im Foundling Hospital konnte noch eine Ode auf die drei führenden englischen Künstler Hogarth, Reynolds und Ramsay vorgetragen werden, 1759 war Reynolds bereits anerkanntermaßen der bedeutendste Künstler, in diesem Jahr konnte er seine Preise für Porträts verdoppeln. I 760 kam es zur ersten öffentlichen Kunstausstellung in England überhaupt, sie wurde getragen von der 1754 gegründeten Society of Arts, einem Zusammenschluß von Kennern, Kunstinteressierten und auch Künstlern, bei dem jedoch die Connoisseurs das Sagen hatten, sie versuchten in diesem Verein ihre Patronage zu organisieren und arbeiteten auf die Gründung einer von ihnen geleiteten Akademie hin. Hogarth nahm an ihrer Ausstellung nicht teil. Er plädierte für eine demokratische Künstlerselbstorganisation, war gegen bestallte Professoren, polemisierte gegen die Patronage und argumentierte für den Wettbewerb auf einem freien Markt.

13 W. Hogarth, The Analysis of Beauty, London 1753 , S. 25 .

54 Ebenda, S. 24.

" Ebenda, Kap. XVII, 3.

56 Die Darstellung folgt vor allem Paulson, op. cit. (Anm. 2), Kap. 25 und 26. 
Im Oktober 1760 starb Georg II., auf seinen Nachfolger Georg III. richteten die Künstler ihre Hoffnungen, auch Hogarth, der 1757 "Sergeant Painter to the King " geworden war. Ende 1760 planten die Künstler die Ausstellung von 1761 , baten wieder die Society of Arts um finanzielle Unterstützung, wollten jedoch über Organisation und Auswahl selbst bestimmen. Die Society of Arts wollte sich das Konzept nicht aus der Hand nehmen lassen, es kam zum Bruch. Die Künstler gründeten die Society of Artists und planten eine eigene Ausstellung. Sofort war Hogarth wieder dabei, versuchte seine demokratischen Vorstellungen zu erläutern, konnte sich jedoch nicht durchsetzen. Immerhin wurde er in den Vorstand gewählt, zu dem nicht nur Reynolds, sondern auch Garrick gehörte. Hogarth stach für den Katalog ein Frontis- und ein Tailpiece, er wurde dadurch zum Verkaufsschlager. Die Ausstellung selbst jedoch endete mit einem großen Erfolg für Reynolds, für Hogarth blieb das Ergebnis unbefriedigend. Immer mehr zeichnete sich als Fernziel der Künstlerplanung die Etablierung einer orthodoxen, hierarchisch aufgebauten Präsidialakademie ab, die schließlich 1768 mit Reynolds als erstem Präsidenten auch gegründet wurde.

I 76r jedoch hatte Garrick mit Freunden den St. James Chronicle ins Leben gerufen, in dem beide Richtungen - verkürzt gesagt: Hogarths realistische, Reynolds idealistische - nebeneinander zu Worte kamen. Offenbar war Garrick das ausgleichende Element zwischen den Fronten, er blieb auch weiterhin gleichermaßen mit Hogarth und Reynolds befreundet. 1762 beteiligte sich Hogarth nicht mehr an der Ausstellung der Society of Artists, sondern organisierte als direkte Parodie auf die Ausstellung der Society of Arts, indirekt aber auch auf die der Society of Artists, eine Sign-Painters-Exhibition, eine Ausstellung also der Ladenschildmaler, und lieferte nicht nur eigene Entwürfe, sondern übermalte auch eine ganze Reihe der eingereichten älteren Schilder. Das Unternehmen ist so absurd nicht: einmal machte Hogarth sich mit dieser Ausstellung über den idealistischen Anspruch der nach Höherem strebenden Künstler lustig, zum anderen bot sich für seine Kunst in der Tat ein Betätigungsfeld, denn die Ladenschilder, die zu dieser Zeit London derartig überschwemmten, daß man gesetzlich gegen sie vorgehen wollte, folgten in den allermeisten Fällen emblematischen Prinzipien, die zwar meist nicht über den bloßen "pun«, das Wortspiel, hinauskamen, grundsätzlich jedoch nicht nach anderen Regeln entstanden als Hogarths und Reynolds Garrick-Porträts. Auch sie arbeiteten mit der Sinnumkehrung klassischer Themen, um sie für gänzliche neue Zwecke verfügbar zu machen. Die Kritik verstand die Absicht der Ausstellung durchaus und wußte ihr auch künstlerisch etwas abzugewinnen. In einer Rezension heißt es charakterischerweise: so wie man über Garricks Satiren lachen könne, ohne den Geschmack an seinen ernsten Stücken zu verlieren, so könne man auch diese Ausstellung goutieren, ohne sich an der wahren Kunst zu versündigen"7. Reynolds hätte das nicht mehr so gesehen. Er hatte in den vierziger und frühen fünfziger Jahren noch Gesellschaftssatiren gemalt, das hielt er später mit den Prinzipien des "grand style * für gänzlich unvereinbar.

So sehr sich Hogarths und Reynolds Garrickbilder auf den ersten Blick von der Konzeption her ähneln: auch in ihnen werden die unterschiedlichen Positionen beider deutlich; Garrick, ihr Medium, nahm eine vermittelnde Stellung ein, tendierte jedoch, je älter und, so muß man wohl sagen, gesellschaftlich erfolgreicher er wurde, immer mehr zu Reynolds Idealismus, der den »gentleman«-Künstler voraussetzte. So konnte er sich schließlich in Reynolds Porträt wiedererkennen, in Hogarths nicht mehr.

s7 Zitiert ebenda, S. 346f. (*Chronicle*, 3.-6. April 1762). 